\title{
Follow up of women with borderline cervical smears as defined by national guidelines
}

\author{
Mark K Heatley
}

\begin{abstract}
Aim-To determine the proportion of women with abnormalities in cervical smears corresponding to borderline nuclear change, as defined by national guidelines, which return to normal or persist as cytological or histological abnormalities.

Methods-313 women with borderline nuclear change diagnosed by a single pathologist using the national criteria were followed up for up to two years.

Results-On initial follow up, $45 \%$ of women had a negative smear or biopsy, $46.5 \%$ had a low grade cytological or histological abnormality, and $8.5 \%$ had a high grade abnormality. Of 81 patients in whom a second follow up smear or biopsy was available, $47 \%$ had no detectable abnormality, $38.5 \%$ had low grade lesion, and $14.5 \%$ had a high grade lesion. In total, 32 patients $(10.2 \%)$ had a high grade lesion (defined as moderate or severe dyskaryosis on smear or CINII or CINIII on biopsy) on at least one follow up sample. Conclusions-The results support the use of the national criteria defining borderline nuclear change in identifying women at increased risk of developing a high grade cervical intraepithelial neoplasia, as identified histologically or cytologically, and highlight the importance of follow up in these patients.

(f Clin Pathol 1999;52:787-788)
\end{abstract}

Keywords: cervix; cervical intraepithelial neoplasia; cytology

Long term follow up of women with borderline nuclear changes on routine cytological screening has shown that a substantial proportion developed high grade dyskaryosis. ${ }^{1}$ More recently the British Society for Clinical Cytology and the Royal College of Pathologists cooperated to produce a series of guidelines defining borderline nuclear changes in cervical smears and provided illustrations to assist in their identification. ${ }^{2}$ The appropriateness of these guidelines has been discussed publicly. ${ }^{3}$

This paper provides details of the follow up of 313 women who have had borderline nuclear changes in their cervical smears diagnosed by a single pathologist using the nationally suggested criteria. ${ }^{2}$

\section{Methods}

The cases had been submitted to the department of pathology at the Jessop Hospital for Women, Sheffield, and the department of cellular pathology at the Taunton and Somerset NHS Trust. ${ }^{4}$ Following primary screening and checking by cytoscreeners and medical laboratory scientific officers as detailed in the relevant departmental protocols, all the slides were examined by a single pathologist. The slides were completely rescreened and the features in the abnormal cells compared with diagnostic criteria provided by the working party. ${ }^{2}$ Where possible, a direct comparison with one of the images provided by the borderline booklet was made. ${ }^{2}$ Only cases in which the changes were located in squamous epithelial cells were studied.

Follow up, limited to up to two years after the index smear, was obtained from the cytopathology and histopathology records of the two departments, other pathology departments, from the patients' general practitioners and from the appropriate commissioning bodies in the relevant health authorities. The criteria used for defining these cytopathological and histopathological abnormalities has been described previously. ${ }^{5-7}$ Post-treatment smears in those patients who received definitive therapy at their first review were not included in these data.

\section{Results}

Borderline nuclear changes were identified in 353 patients. No follow up was available in 40 patients. Of the remaining 313 patients, $45 \%$ had a negative smear or biopsy on initial follow up, $46.5 \%$ had a low grade abnormality (that is, a borderline or mildly dyskaryotic smear or CINI on biopsy) on repeat smear or biopsy, and $8.5 \%$ had a high grade abnormality (moderate or severe dyskaryosis on smear or CINII or III on biopsy) on repeat smear or biopsy (table 1). In 232 cases no further follow up was available. Thirty five per cent of these had had a negative smear on first review, 56\% had had mild dyskaryosis or CINI, and $9 \%$ had had moderate or severe dyskaryosis or CINII or CINIII. In 81 cases a second repeat smear or biopsy was available. In $47 \%$ of these cases there was no abnormality detected, $38.5 \%$ had a low grade abnormality, and $14.5 \%$ had a high grade abnormality on this second repeat smear or biopsy (table 1$)$. In all, 32 patients $(10.2 \%)$ had a high grade dyskaryosis or high grade CIN lesion which developed within two years of the index borderline smears. Table 2 compares the findings on the first and second repeat smear or biopsy after the initial borderline diagnosis.

\section{Discussion}

There is a greater chance that women with borderline smears will be found subsequently to have high grade cervical abnormalities than 
Table 1 Results of follow up in 313 women diagnosed with borderline smears using national criteria. All of the women had a biopsy or repeat smear (first review) and in 81 the results of a further second (repeat) biopsy or smear were available (second review)

\begin{tabular}{|c|c|c|c|c|c|c|c|c|c|c|}
\hline & \multicolumn{2}{|c|}{$\begin{array}{l}\text { Results of cytological } \\
\text { follow up }\end{array}$} & \multicolumn{3}{|c|}{ Dyskaryosis } & \multicolumn{4}{|c|}{ Results of histological follow up } & \multirow[b]{2}{*}{ Total } \\
\hline & Negative & $B N C$ & Mild & Moderate & Severe & Negative & CINI & CINII & CINIII & \\
\hline First review & $\begin{array}{l}117 \\
36 \%\end{array}$ & $\begin{array}{l}55 \\
18 \%\end{array}$ & $\begin{array}{l}11 \\
3.5 \%\end{array}$ & $\begin{array}{l}10 \\
3 \%\end{array}$ & $\begin{array}{l}1 \\
0.5 \%\end{array}$ & $\begin{array}{l}27 \\
9 \%\end{array}$ & $\begin{array}{l}77 \\
25 \%\end{array}$ & $\begin{array}{l}12 \\
4 \%\end{array}$ & $\begin{array}{l}3 \\
1 \%\end{array}$ & 313 \\
\hline Second review & $\begin{array}{l}31 \\
38 \%\end{array}$ & $\begin{array}{l}5 \\
6 \%\end{array}$ & $\begin{array}{l}2 \\
2.5 \%\end{array}$ & $\begin{array}{l}1 \\
1.2 \%\end{array}$ & $\begin{array}{l}1 \\
1.2 \%\end{array}$ & $\begin{array}{l}7 \\
9 \%\end{array}$ & $\begin{array}{l}24 \\
30 \%\end{array}$ & $\begin{array}{l}5 \\
6 \%\end{array}$ & $\begin{array}{l}5 \\
6 \%\end{array}$ & 81 \\
\hline
\end{tabular}

$\mathrm{BNC}$, borderline nuclear change; CIN, cervical intraepithelial neoplasia.

Table 2 Comparison of findings on second review with the results of the first review in 81 women in whom both were available following an initial borderline smear

\begin{tabular}{|c|c|c|c|c|c|c|c|c|c|c|}
\hline \multirow[b]{3}{*}{ First review } & \multicolumn{10}{|c|}{ Second review } \\
\hline & \multicolumn{5}{|c|}{ Follow up with cytology (dyskaryosis) } & \multicolumn{4}{|c|}{ Follow up with histology } & \multirow[b]{2}{*}{ Total } \\
\hline & Negative & $B N C$ & Mild & Moderate & Severe & Negative & CINI & CINII & CINIII & \\
\hline \multicolumn{11}{|l|}{ Cytology } \\
\hline Negative & 30 & 2 & 0 & 1 & 0 & 5 & 5 & 2 & 0 & 45 \\
\hline $\mathrm{BNC}$ & 0 & 3 & 0 & 0 & 1 & 1 & 13 & 2 & 0 & 20 \\
\hline \multicolumn{11}{|l|}{ Dyskaryosis } \\
\hline Mild & 1 & 0 & 2 & 0 & 0 & 0 & 2 & 0 & 0 & 5 \\
\hline Moderate & 0 & 0 & 0 & 0 & 0 & 1 & 0 & 1 & 5 & 7 \\
\hline \multicolumn{11}{|l|}{ Histology } \\
\hline CINI & 0 & 0 & 0 & 0 & 0 & 0 & 4 & 0 & 0 & 4 \\
\hline Total & 31 & 5 & 2 & 1 & 1 & 7 & 24 & 5 & 5 & 81 \\
\hline
\end{tabular}

BNC, borderline nuclear change; CIN, cervical intraepithelial neoplasia.

those with reactive changes. ${ }^{8}$ This study indicates that $10.2 \%$ of women developed a high grade dyskaryosis or CIN lesion within two years of having a borderline smear. Hirschowitz et al found that $22.4 \%$ of women with borderline cytological changes had a smear test showing high grade dyskaryosis which developed between 13 and 106 months after the index smear. ${ }^{1}$ Fifty per cent of these women, or $11.2 \%$ of their total study group, developed their high grade lesion within 34 months. The frequency with which a high grade lesion was identified after a borderline smear was therefore similar in the two studies. This study, however, is the first to use the national guidelines ${ }^{2}$ to define the borderline smears.

The presence of a low grade lesion in seven women and of a high grade lesion in three women who had a negative smear following the initial borderline diagnosis (table 2) supports the current policy of requiring that a women has at least two negative smears before she is returned to routine follow up. ${ }^{9}$ In 20 women on first review (table 2) the smear showed borderline nuclear change and of these only one had a subsequent negative biopsy, the remainder showing low grade abnormality (16 cases) or high grade abnormality (three cases). This highlights the importance of continued follow up in women with a persistent borderline abnormality. ${ }^{9}$ Nine women had mild dyskaryosis or CINI on smear or biopsy as an initial investigation on first review (table 2). One of these patients had a subsequent negative smear and the remaining eight women showed no evidence of progression or regression, highlighting the relative stability of this lesion. ${ }^{10-12}$

This follow up study confirms the previous suggestion that borderline smears are associ- ated with the subsequent diagnosis of high grade cervical lesions in about one tenth of women in the short term, possibly because in some cases they were underrepresented on the index smear. It provides evidence to support the validity of the borderline document ${ }^{2}$ and justifies the careful follow up of women with borderline smears which has been recommended nationally. ${ }^{9}$

I should like to thank Dr Jerry O'Sullivan, St Richards Hospital, Chichester for reading the manuscript, and also Mrs Jill Gosney for secretarial assistance.

1 Hirschowitz L, Raffle AK, Mackenzie EFD, et al. Long term follow up of women with borderline cervical smear test results: effects of age and viral infection on progression to high grade dyskaryosis. BMF 1992;304:1209-12.

2 Working Party of National Coordinating Network (National Cervical Screening Programme) British Society for Clinical Cytology and the Royal College of Pathologists. Borderline nuclear changes in cervical smears: guidelines on their recognition and management. $f$ Clin Pathol 1994;47:481-92.

3 Slater DN. Borderline smears: have the guidelines lessened the confusion or increased it? Cytopathology 1996;7:73-4.

4 Heatley MK. The borderline cervical smear [letter]. Heatley MK. The borderlin
Cytopathology 1996;7:424-5.

5 Buckley CH, Butler EB, Fox H. Cervical intraepithelial neoplasia. F Clin Pathol 1982;35:1-13.

6 Anderson MC, Brown CL, Buckley CH, et al. Current views on cervical intraepithelial neoplasia. f Clin Pathol 1991;44: 969-78.

7 Evans DMD, Hudson EA, Brown CL, et al. Terminology in gynaecological cytopathology: report of the Working Party of the British Society for Clinical Cytology. F Clin Pathol 1986;39:933-44.

8 Parham DM, Wiredu EK, Hussein KA. Significance of borderline nuclear abnormality in cervical smears. Cytopatholderline nuclear ab

9 Herbert A. Achievable standards, benchmarks for reporting, criteria for evaluation of cervical cytopathology. Cytopathology 1995;6(suppl 2).

10 Fu YS, Robboy SJ, Prat J. Nuclear DNA study of vaginal and cervical squamous cell abnormalities in DES exposed pregnancy. Obstet Gynecol 1978;52:129-37.

11 Fu YS, Reagan JW, Richart RM. Definition of precursors. Gynecol Oncol 1981;12:S220-31.

12 Bibbo M, Dytch HE, Alenghat E, et al. DNA ploidy profiles as prognostic indicators in CIN lesions. Am $\mathcal{F}$ Clin Pathol 1989;92:261-5. 